\title{
Skeletal Age as a Determinant of Phalangeal Quantitative Ultrasound Measures of Bone Quality in Children and Adolescents
}

\author{
M. Vignolo ${ }^{*}, 1$, C. Torrisi ${ }^{1}$, A. Parodi ${ }^{1}$, F. Becchetti ${ }^{1}$, F. De Terlizzi ${ }^{2}$ and G. Aicardi ${ }^{1}$

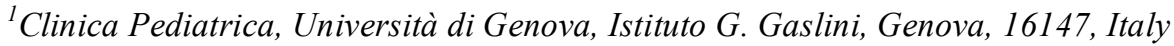 \\ ${ }^{2}$ IGEA Biophysics Laboratori, Carpi, Modena, Italy
}

\begin{abstract}
Background: Quantitative ultrasonography of the proximal phalanges of the hand (QUS) has emerged as an attractive technical choice to assess bone quality features both in terms of bone mass and structure. Strong associations were found between QUS measures, chronological age and growth variables, such height, weight and pubertal stages. Aim: To evaluate the relationship between skeletal age and QUS variables and the influence of skeletal age on QUS variables after allowing for chronological age, height, weight and pubertal stage. Subjects and Methods: 235 healthy children and adolescents ( 85 boys and 150 girls) aged 3 - 18 years were examined. Height, weight, body mass index (BMI) were collected. Skeletal age was assessed by the third version of Tanner-Whitehouse method (TW3). QUS variables amplitude dependent speed of sound (AD-SoS, m/s) and bone transmission time (BTT, $\mu \mathrm{sec}$ ) were measured by DBM Sonic BP IGEA sonograph. Results: Statistically significant positive correlations were found between AD-SoS and BTT and skeletal age ( $\mathrm{R} 2=0.76$ in boys and 0.83 in girls for AD-SoS and 0.96 in boys and 0.93 in girls for BTT). A very close correlation was observed between skeletal age and BTT even after adjusting for chronological age, height, weight, and pubertal stage. In both sexes, chronological age, height and BTT resulted significant predictors of skeletal age. Conclusion: Skeletal age has emerged as an important determinant of phalangeal QUS measurements, mainly BTT. Skeletal maturity should be taken into account when QUS technology is used to evaluate bone mass and structure in children.
\end{abstract}

Keywords: Skeletal age, quantitative ultrasound technique, bone.

\section{INTRODUCTION}

Among the techniques available to assess bone quality, quantitative ultrasonography of the proximal phalanges of the hand (QUS) has emerged as a particularly attractive technical choice for paediatric studies. It is easy to use and avoids radiation, allowing repeated measurements [1-3].

The QUS method is based on the transmission of ultrasound through the distal end of the proximal phalangeal diaphysis of the hand. The graphic tracing obtained reflects the characteristics of the electrical signal generated by US after going through the phalanx soft tissues and bone. QUS variables give reliable information about bone size, bone mass accumulation and bone tissue quality features [1,2,4-7].

Studies have demonstrated the efficacy of the technique in identifying bone tissue changes in children with celiac disease [8], acute lymphoblastic leucemia, [9], genetic diseases [10], renal impairment [11], HIV vertical infection [12], diabetes mellitus $[13,14]$ and other bone and mineral disorders [15].

Normal ranges of QUS variables $\mathrm{AD}-\mathrm{SoS}$ and $\mathrm{BTT}$ for children and adolescents have been produced [16-19] and longitudinal QUS measurements revealed that both AD-SoS and BTT measurements are accurate [20].

*Address correspondence to this author at the Pediatric Clinic, G. Gaslini Institute, Largo Gaslini, 16100, Genoa, Italy; Tel: +390105636330; Fax: +39010 3538265; E-mail: obesità@ospedale-gaslini.ge.it
Strong associations were found between QUS measures, chronological age and growth variables such as height, weight and pubertal stage [17,19], while the influence of skeletal maturity on QUS measurements has not been evaluated yet.

This may be of interest since some studies using DXA technology, total body or regional, have shown that skeletal age is a powerful determinant of bone mineralization $[21,22]$.

The aims of this study were, therefore, to evaluate: 1) the relationship between skeletal age and QUS variables, 2) if skeletal age influences QUS variables after allowing for chronological age, height, weight and pubertal stage.

\section{SUBJECTS AND METHODS}

235 healthy children and adolescents ( 85 boys and 150 girls) aged $3-18$ years were examined. The children were evaluated by a paediatrician who excluded bone and joint diseases, endocrine or systemic diseases known to influence growth, genetic or dysmorphic syndromes, overweight/ obesity, hand and wrist deformities, fractures in the previous six months, or soft tissue swelling, illness that interrupted physical activity for 1 month or more in the year before enrolment. Subjects receiving current or previous chronic medication including glucocorticoids or anabolic steroid treatment, gonadotropin inhibitors, GH treatment, anticonvulsants were also excluded. 
Their heights and weights were between the 3rd and 97th percentiles of the growth charts of Tanner and Whitehouse (1976) [23]. For girls, inclusion criteria consisted of breast development occurring between 8 and $13 \mathrm{yr}$, menarche between 10 and $15 \mathrm{yr}$, and no pubic hair before $7 \mathrm{yr}$ of age. For boys, inclusion criteria consisted of testicular size $<4 \mathrm{cc}$ by 9 years and $>4 \mathrm{cc}$ by 14 years of age.

$45 \%$ were healthy subjects seen for adult height prediction, $56 \%$ were referred for suspected growth disorders that were successively excluded on the basis of clinical evaluations.

Informed written consent to enter the study was obtained from parents of all the children examined. Approval by the local ethics committee was also obtained.

Height was measured to the nearest $0.1 \mathrm{~cm}$ with a Harpenden stadiometer and weight was recorded to the nearest $0.1 \mathrm{Kg}$ with an electronic digital scale.

Body mass index (BMI $-\mathrm{kg} / \mathrm{m}^{2}$ ) was calculated by dividing weight $(\mathrm{kg})$ by squared stature $\left(\mathrm{m}^{2}\right)$.

Pubertal development was evaluated by assessment of breast stage in girls and genitalia stage in boys obtained by a pediatrician according to Tanner's criteria (1976).

Skeletal age in years was assessed through an anteroposterior X-ray of the left hand and wrist according to the TW3 method [24]. This method, developed as a revision of the TW2 system, is based on scoring the stages of bone development of 13 epiphyses of the radius, ulna and long bones of the hand. The TW3 reference values have proven to match closely skeletal maturation in Italian children and adolescents [25]. Assessments were made by the same experienced assessor (reproducibility expressed as standard error of measurement: 0.232 years).

QUS variables were measured by the sonographic device DBM Sonic BP IGEA (Carpi, Italy). The device employs two $12 \mathrm{~mm}$ diameter and $1.25 \mathrm{MHz}$ transducers assembled on a high precision caliper that measures the distance between emitting and receiving probes positioned on the lateral and medial surfaces of digits II-V at the distal end of the diaphysis of the first phalanges in the proximity of the condyles. The non-dominant hand was analyzed as recommended by the manufacturer.

The following QUS variables were examined:

- $\quad$ amplitude dependent speed of sound (AD-SoS, m/s), i.e. the velocity at which the US cross the phalanx, calculated dividing the time taken by the first signal to be received with a predetermined minimum amplitude value $(2 \mathrm{mV})$ by the distance between the probes. This variable is influenced by structural organization of growing bone and, to a lesser extent, by bone density and size;

- bone transmission time (BTT, $\mu$ sec), i.e. the difference between transmission time in phalanx soft tissue and bone and transmission time in phalanx soft tissue. The impact of soft tissue thickness on this QUS variable is expected to be minimal.

Measurements were performed by trained assessors (MV, AM and AP). Quality assurance was based on the daily calibration of an IGEA standard Plexiglas cube. A quality control procedure was performed using a cross calibration phantom. The calibration device was checked by the manufacturer twice a year. The intra-operator repeatability measured as coefficient of variation of the AD-SoS was $0.96 \%, 0.97 \%$ and $0.97 \%$ for evaluator $\mathrm{MV}, \mathrm{AM}$ and $\mathrm{AP}$ respectively.

There were no statistical differences between measures of AD-SoS obtained by the different evaluators (reproducibility: mean $\mathrm{CV} \% 0.96$ ).

The BTT inter and intra-observer precision was very similar (repeatability: $\mathrm{CV} \%=0.98 \%, 0.96 \%$ and $0.97 \%$; reproducibility: $\mathrm{CV} \%=0.97 \%$ ).

\section{Statistical Analysis}

Statistical analysis was carried out using SPSS 13.0 software (SPSS Inc, MA, US).

Descriptive analyses were reported as mean and standard deviation of continuous variables, while frequency description was provided for pubertal stages for both sexes separately.

Linear regression analysis was performed to determine the association among QUS parameters and auxological and anthropometric variables, as well as skeletal age; the correlation coefficient was reported together with SEE (standard error of estimate), intercept and its standard error, coefficient of independent variable and its standard error, level of significance.

Partial correlation analysis between AD-SoS and BTT and skeletal age, adjusting for chronological age, height, weight and pubertal stage was performed for boys and girls separately to determine the association between QUS parameters and skeletal age allowing for other auxological and growth variables.

Multiple regression analysis including chronological age, height, weight, BMI, skeletal age, Tanner stage of sexual development, and BTT was also performed to identify the significant predictors of skeletal age among QUS and auxological/anthropometric variables. For each model, correlation coefficient and SEE were reported, and the contribution of each significant variable in the model was given in terms of coefficient, standard error, standardized coefficient (Beta), $t$ value, and level of significance.

\section{RESULTS}

Basic information on the study population is given in Table 1.

Statistically significant positive correlation was found between AD-SoS and BTT, and chronological age, height, weight, BMI, pubertal stage.

Correlations between QUS variables and skeletal age, in boys and girls separately, with the estimates of the constants, are reported in Table $\mathbf{2}$. A very close correlation was observed between skeletal age and BTT. 
Table 1. Age and Growth Variables of 85 Boys and 150 Girls and Subjects Distribution according to Pubertal Tanner's Stage

\begin{tabular}{|c|c|c|c|c|}
\hline & \multicolumn{2}{|c|}{ Boys } & \multicolumn{2}{|c|}{ Girls } \\
\hline & Mean & SD & Mean & SD \\
\hline Age (years) & 9,74 & 3,7 & 9,24 & 2,72 \\
\hline Height $(\mathrm{cm})$ & 133,5 & 22,2 & 131,5 & 16,6 \\
\hline Height SDS & $-0,3$ & 1,2 & 0.00 & 1,3 \\
\hline Weight $(\mathrm{Kg})$ & 33,1 & 14,7 & 31,7 & 11,5 \\
\hline BMI $\left(\mathrm{Kg} / \mathrm{m}^{2}\right)$ & 17,62 & 2,66 & 17,7 & 3,03 \\
\hline BMI-SDS & 0,36 & 1,31 & 0,62 & 1,32 \\
\hline Skeletal age (years) & 9,5 & 3,70 & 9,3 & 2,8 \\
\hline AD-SoS (m/sec) & 1910 & 62 & 1925 & 53 \\
\hline BTT $(\mu \mathrm{sec})$ & 0,93 & 0,28 & 0,89 & 0,23 \\
\hline $\begin{array}{c}\text { Pubertal } \\
\text { Tanner's stage }\end{array}$ & $\begin{array}{c}\text { stage 1 } \\
\text { stage } \\
\text { stage } \\
\text { stage } 4 \\
\text { stage }\end{array}$ & $\begin{array}{l}=47 \\
=9 \\
=6 \\
=11 \\
=9\end{array}$ & $\begin{array}{c}\text { stage 1 } \\
\text { stage } 2 \\
\text { stage } 3 \\
\text { stage } \\
\text { stage } 5\end{array}$ & $\begin{array}{l}=75 \\
=37 \\
=17 \\
=5 \\
=14\end{array}$ \\
\hline
\end{tabular}

Table 2. Linear Regression Analysis for AD-SoS and BTT as Functions of Skeletal Age

\begin{tabular}{|c|c|c|c|c|c|c|}
\hline Skeletal age & \multicolumn{3}{|c|}{ Boys } & \multicolumn{3}{c|}{ Girls } \\
\hline Terms & costant & SE & P & Costant & SE & P \\
\hline \hline Intercept & $-91,0$ & 6,2 & $<0,0001$ & $-84,1$ & 3,5 & $<0,0001$ \\
\hline AD-SoS & 0,053 & 0,003 & $<0,0001$ & 0,049 & 0,002 & $<0,0001$ \\
\hline R2 & \multicolumn{3}{|c|}{0,76} & 0,83 & & \\
\hline SEE & \multicolumn{3}{|c|}{1,85} & 1,17 & & \\
\hline
\end{tabular}

\begin{tabular}{|c|c|c|c|c|c|c|}
\hline Skeletal age & \multicolumn{3}{|c|}{ Boys } & \multicolumn{3}{c|}{ Girls } \\
\hline Terms & costant & SE & P & Costant & SE & P \\
\hline \hline Intercept & 2,49 & 0,28 & $<0,0001$ & $-1,30$ & 0,24 & $<0,0001$ \\
\hline BTT & 12,88 & 0,29 & $<0,0001$ & 11,86 & 0,27 & $<0,0001$ \\
\hline R2 & \multicolumn{3}{|c|}{0,96} & 0,93 & & \\
\hline SEE & \multicolumn{3}{|c|}{0,76} & 0,74 & & \\
\hline
\end{tabular}

Figs. (1-2) show BTT values as a function of skeletal age and fitted regression curves for boys and girls separately.

A partial correlation analysis between AD-SoS and BTT and skeletal age, adjusting for chronological age, height, weight, and pubertal stage showed highly significant values of correlation coefficients as regards BTT (in boys: $r=$ $0.697, \mathrm{p}<0.0001$ and in girls: $r=0.602, p<0.0001$ ), while partial correlations between skeletal age and AD-SoS are lower (in boys: $r=0.145, p$ N.S. and in girls: $r=0.380$, $\mathrm{p}<0.0001)$.

In order to test the independent influence of growth variables on skeletal age, a multivariate linear regression model including chronological age, height, weight, BMI, pubertal stage and BTT with skeletal age as dependent variable was fitted.

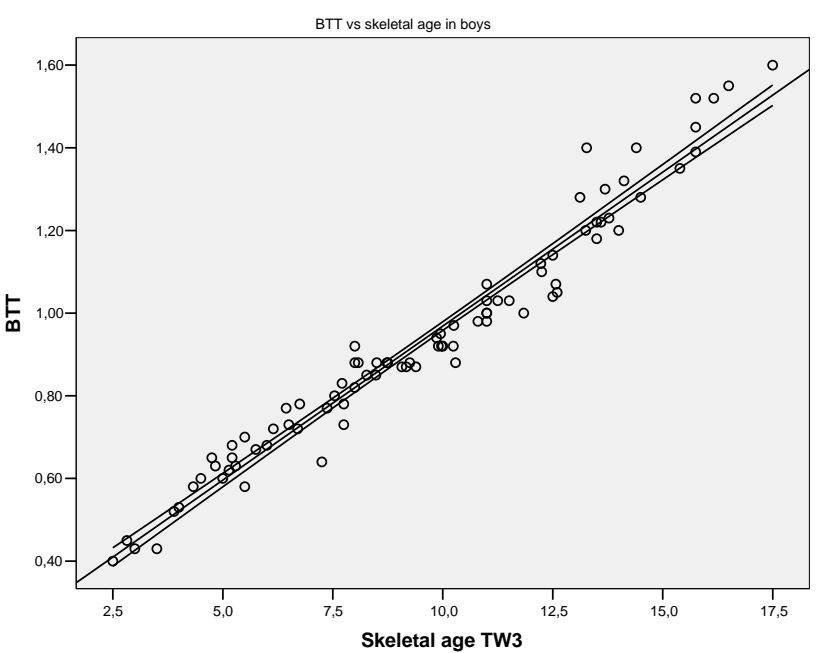

Fig. (1). BTT values as a function of skeletal age and fitted regression curves for boys.

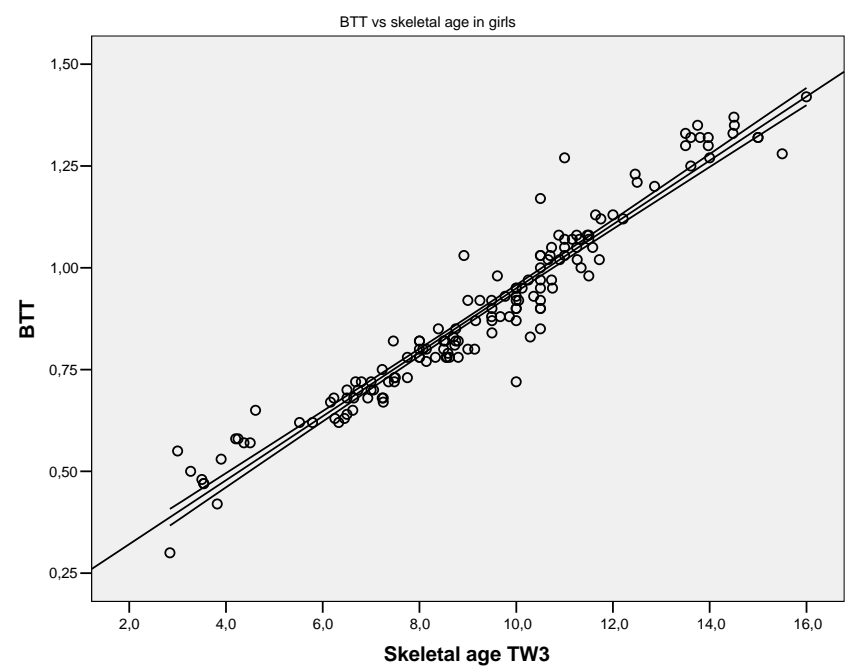

Fig. (2). BTT values as a function of skeletal age and fitted regression curves for girls.

In both sexes, only chronological age, height and BTT resulted as significant predictors of skeletal age (Table $\mathbf{3}$ ).

\section{DISCUSSION}

This study further confirms that phalangeal QUS values in children and adolescents are strongly chronological age and growth related. Among the auxological variables considered, skeletal age has emerged as the most significant determinant of phalangeal QUS both as regards AD-SoS and BTT measurements. In particular, a close relationship was found between skeletal age and BTT, i.e. the US transmission time of through the bone without phalanx soft tissue interference after adjusting for chronological age, height, weight, and pubertal stage. 
Table 3. Linear Multivariate Analysis for Boys and Girls. Dependent Variable: Skeletal Age

\begin{tabular}{|c|c|c|c|c|c|c|c|c|c|c|}
\hline \multirow{2}{*}{$\begin{array}{c}\text { BTT } \\
\text { Terms }\end{array}$} & \multicolumn{5}{|c|}{ Boys } & \multicolumn{5}{|c|}{ Girls } \\
\hline & costant & SE & Beta & $\mathbf{t}$ & $\mathbf{P}$ & Costant & SE & Beta & $\mathbf{t}$ & $\mathbf{P}$ \\
\hline Intercept & $-2,536$ & 0,444 & & $-5,718$ & $<0,0001$ & $-2,098$ & 0,461 & & $-4,547$ & $<0,0001$ \\
\hline Chronological Age & 0,527 & 0,044 & 0,522 & 12,054 & $<0,0001$ & 0,545 & 0,049 & 0,527 & 11,064 & $<0,0001$ \\
\hline Height & 0,016 & 0,006 & 0,093 & 2,748 & 0,007 & 0,016 & 0,006 & 0,097 & 2,980 & 0,003 \\
\hline BTT & 5,199 & 0,523 & 0,395 & 9,945 & $<0,0001$ & 4,693 & 0,532 & 0,382 & 8,816 & $<0,0001$ \\
\hline SEE & \multicolumn{5}{|c|}{0,39} & \multicolumn{5}{|c|}{0,48} \\
\hline
\end{tabular}

On the whole, these findings are in agreement with other studies which examined the relationship between skeletal age and bone mass in children, using DEXA measurements of bone mineral density of lumbar spine [21], forearm [26] or total body [27]. In the studies by Glastre et al. [21] and Mazess et al. [26], skeletal age was assessed according to the Greulich-Pyle method, while Ilich et al. used the FELS method.

This agreement with studies using quite different techniques, regions of bone mass measurements, and methods to assess skeletal age, clearly confirm that skeletal age, as expression of biological maturation timing, is an important determinant of bone mass in youths.

Moreover, since skeletal age influences QUS variable BTT even independently of chronological age, height, weight, and pubertal stage, skeletal age should be taken into consideration when QUS measurements are used to evaluate bone mass and structure in children and adolescents suffering from diseases able to interfere with growth and bone mineralization.

Given the high correlation of skeletal age with DEXA- or sonography-based measurements of bone mass/quality, some studies have proposed these techniques as a possible alternative to conventional radiographic evaluation of skeletal age obtained by observing the morphological changes of the growing skeleton [28-30].

In our study, chronological age, height and BTT resulted as significant predictors of skeletal age, suggesting that skeletal maturity may be estimated using algorithms based on QUS-BTT measurement, chronological age and height.

This may be of practical interest since skeletal maturity assessment has an essential role both in paediatric clinical practice and research to determine whether and how maturation is affected.

QUS technology, allowing repeated performances, safely and reliably, of bone tissue measurements, seems to have the potential to follow skeletal maturation during the growing period. In any case, further studies, even performed on a longitudinal basis, are required to determine the agreement limits of radiographic skeletal age assessments and skeletal maturity estimates obtained with BTT-QUS based algorithms, both in healthy subjects and in children with growth disorders or pathological conditions involving bone mass accretion.
Finally, a limitation in this study has to be recognized, since the population examined was composed of about half subjects seen for a suspected growth disorder, successively excluded. This may result in over-recruitment of children with even large differences between chronological and skeletal age. Since ethical considerations make impossible to perform X-rays in healthy children, in this study inclusion/ exclusion criteria were adopted to minimize this effect. In any case, in subjects examined in the present study, skeletal age ranged within \pm 2 standard deviations from chronological age.

In conclusion, the present study would confirm that a high relationship is present between phalangeal QUS measurements, mainly BTT, and skeletal age in children and adolescents.

Moreover, findings seem to indicate that skeletal maturity should be necessarily taken into account when QUS technology is used to evaluate bone status in children. However, further studies are required to evaluate if QUS BTT measurements, providing information on skeletal maturity safely and easily, may become a possible alternative to conventional radiographic evaluation of skeletal age.

\section{REFERENCES}

[1] Barkmann R, Lüsse S, Stampa B, et al. Assessment of the geometry of human finger phalanges using quantitative ultrasound in vivo. Osteoporos Int 2000; 11: 745-55.

[2] Halaba ZP, Pluskiewicz W. Quantitative ultrasound in the assessment of skeletal status in children and adolescents. Ultrasound Med Biol 2004; 30: 239-43.

[3] Wuster C, Albanese C, De Aloysio D, et al. Phalangeal osteosonogrammetry study: age related changes, diagnostic sensitivity, and discrimination power. The Phalangeal Osteosonogrammetry Study Group. J Bone Miner Res 2000; 15: 1603-1614.

[4] Njeh CF, Richards A, Boivin CM, et al. Factors influencing the speed of sound through the proximal phalanges. J Clin Densitom 1999; 2: 241-249.

[5] Baroncelli GI, Federico G, Bertelloni S, et al. Bone quality assessment by quantitative ultrasound of proximal phalanxes of the hand in healthy subjects aged 3-21 years. Pediatr Res 2001; 49: 713-18.

[6] Barkmann R, Rohrschneider W, Vierling M, et al. German pediatric reference data for quantitative transverse transmission ultrasound of finger phalanges. Osteoporos Int 2002; 13(1): 55-61.

[7] Fricke O, Tutlewski B, Schwahn B, Schoenau E. Speed of sound: relation to geometric characteristics of bone in children, adolescents, and adults. J Pediatr 2005; 146(6): 764-8. 
[8] Pedrera JD, Lopez MJ, Canal ML, et al. Quantitative phalangeal bone ultrasound is normal after long-term gluten-free diet in young coeliac patients. Eur J Gastroenterol Hepatol 2001; 13: 1169-73.

[9] Pluskiewicz W, Halaba Z, Chelmecka L, et al. Skeletal status in survivors of acute lymphoblastic leukemia assessed by quantitative ultrasound at the hand phalanges: A longitudinal study. Ultrasound Med Biol 2004; 30: 893-8.

[10] Pluskiewicz W, Pyrkosz A, Drozdzowska B, et al. Quantitative ultrasound of the hand phalanges in patients with genetic disorders: a pilot case-control study. Osteoporos Int 2003; 14: 787-92.

[11] Pluskiewicz W, Adamczyk P, Drozdzowska B, et al. Skeletal status in adolescents with end-stage renal failure: A longitudinal study. Osteoporos Int 2005; 16: 289-95.

[12] Rosso R, Vignolo M, Parodi A, et al. Bone quality in perinatally HIV-infected children: role of age, sex, growth,HIV infection, and antiretroviral therapy. AIDS Res Hum Retroviruses 2005; 21: 927 32.

[13] Valerio G, del Puente A, Buono P, et al. Quantitative ultrasound of proximal phalanxes in patients with type 1 diabetes mellitus. Diabetes Res Clin Pract 2004; 64: 161-6.

[14] Damilakis J, Galanakis E, Mamoulakis D, et al. Quantitative ultrasound measurements in children and adolescents with: type 1 diabetes. Calcif Tissue Int 2004; 74: 424-8.

[15] Baroncelli GI, Federico G, Bertelloni S, et al. Assessment of bone quality by quantitative ultrasound of proximal phalanges of the hand and fracture rate in children and adolescents with bone and mineral disorders. Pediatr Res 2003; 54: 125-36.

[16] Halaba Z, Pluskiewicz W. The assessment of development of bone mass in children by quantitative ultrasound through the proximal phalanxes of the hand. Ultrasound Med Biol 1997; 23: 1331-5.

[17] Vignolo M, Brignone A, Mascagni A, et al. Influence of age, sex, and growth variables on phalangeal quantitative ultrasound measures: a study in healthy children and adolescents. Calcif Tissue Int 2003; 72: 681-8.

[18] Gimeno-Ballester J, Azcona San Julian C, Sierrasesumaga Ariznabarreta L. Bone mineral density determination by osteosonography in healthy children and adolescents: normal values. An Esp Pediatr 2001; 54: 540-6.
[19] Baroncelli GI, Federico G, Vignolo M, et al. Cross-sectional reference data for phalangeal quantitative ultrasound from early childhood to young-adulthood according to gender, age, skeletal growth, and pubertal development. Bone 2006; 39: 159-73.

[20] Vignolo M, Parodi A, Mascagni A, et al. Longitudinal assessment of bone quality by quantitative ultrasonography in children and adolescents. Ultrasound Med Biol 2006; 32: 1003-10.

[21] Glastre C, Braillon P, David L, et al. Measurement of bone mineral content of the lumbar spine by dual energy $\mathrm{X}$-ray absorptiometry in normal children: correlations with growth parameters. J Clin Endocrinol Metab 1990; 70: 1330-3.

[22] Ilich JZ, Hsieh LC, Tzagournis MA, et al. A comparison of single photon and dual X-ray absorptiometry of the forearm in children and adults. Bone 1994; 15: 187-91.

[23] Tanner JM, Whitehouse R.H. Clinical longitudinal standards for height, weight, height velocity, weight velocity, and stages of puberty. Arch Dis Child 1976; 51: 170-9.

[24] Tanner JM, Healy MJR, Goldstein H, Cameron N. Assessment of skeletal maturity. London: W.B. Saunders 2001.

[25] Vignolo M, Naselli A, Magliano P, et al. Use of the new US90 standards for TW-RUS skeletal maturity scores in youths from the Italian population. Horm Res 1999; 51: 168-72.

[26] Mazess RB, Cameron JR. Skeletal growth in school children: maturation and bone mass. Am J Phys Anthropol 1971; 35: 399407.

[27] Ilich JZ, Hangartner TN, Skugor M, et al. Skeletal age as a determinant of bone mass in preadolescent females. Skeletal Radiol 1996; 25: 431-9.

[28] Braillon PM, Guibal AL, Pracros-Deffrenne P, et al. Dual energy $\mathrm{X}$-ray absorptiometry of the hand and wrist--a possible technique to assess skeletal maturation: methodology and data in normal youths. Acta Paediatr 1998; 87(9): 924-9.

[29] Bilgili Y, Hizel S, Kara SA et al. Accuracy of skeletal age assessment in children from birth to 6 years of age with the ultrasonographic version of the Greulich-Pyle atlas. J Ultrasound Med 2003; 22(7): 683-90.

[30] Mentzel HJ, Vilser C, Eulenstein M, et al. Assessment of skeletal age at the wrist in children with a new ultrasound device. Pediatr Radiol 2005; 35(4): 429-33.

(C) Vignolo et al.; Licensee Bentham Open.

This is an open access article licensed under the terms of the Creative Commons Attribution Non-Commercial License (http://creativecommons.org/licenses/by$\mathrm{nc} / 3.0 /$ ), which permits unrestricted, non-commercial use, distribution and reproduction in any medium, provided the work is properly cited. 